\title{
Contact-induced phenomena in Lokono (Arawakan)
}

\section{Introduction}

This chapter describes contact-induced language changes in a variety of Lokono spoken in Suriname. Setting out from an account of the different layers of older nominal borrowings, I move on to discuss synchronic examples of structural borrowing. This shift in borrowing patterns is a symptom of a new contact situation in the history of Lokono. The widespread multilingualism in Lokono, Sranantongo, and Surinamese Dutch in the Lokono communities makes it possible for the languages to exert influence on one another that penetrates beyond lexical borrowing. This is particularly conspicuous in the domain of strategies for marking relations between clauses, where strategies from Sranantongo and Surinamese Dutch compete with the Lokono equivalents and introduce new grammatical distinctions into the Lokono grammar.

Language contact in the Guianas is a multidimensional jigsaw puzzle, a reflection of the complex linguistic history of the region and the social, economic, and political relations between the different peoples, both in the past and in the present. ${ }^{1}$ This chapter situates the Lokono language and its speakers within the framework of Surinamese contact-induced phenomena. ${ }^{2}$ As a necessary background, in section 2 I first outline the present-day Lokono sociolinguistic situation. Sections 3 and 4 discuss lexical and structural borrowing, respectively. In section 3, I sketch the history of contact between the Lokono and other peoples and review the layers of borrowing resulting from these interactions. In section 4, I move on to the discussion of the structural influence of Lokono on Surinamese

\footnotetext{
1 I am greatly indebted to the members of the Lokono community for teaching me their language and for helping me collect and analyze the data. In particular, I want to thank Purci Martin, Ursula Visser-Biswane, and Sonia Orassie. I also want to thank my colleagues, Eithne Carlin, Kees Hengeveld, Pieter Muysken, Kofi Yakpo, and Swintha Danielsen, the editors, and anonymous reviewers for comments on the chapter.

2 I use the term Lokono to refer to the language and the people speaking this particular Arawakan language, which is an established practice in Arawakan linguistics and in the community. However, the language is also known as Arawak (Arowak in Dutch) and some speakers prefer this term instead of Lokono, as Lokono means also 'Amerindians' and even 'people' in general.
} 
Dutch and Sranantongo and vice versa. The chapter ends with conclusions in section 5 .

\section{Sociolinguistic background}

The Lokono people inhabit the northern parts of the Guianas (Guyana, Suriname, and French Guiana), including both the coastal urban centers (Georgetown, Paramaribo, and Cayenne) and the rural villages scattered throughout the pericoastal savannahs. Though exact statistical information is unavailable, probably half of the Surinamese ethnic Lokono population lives in the capital city Paramaribo and its suburbs, while the indigenous villages are on the whole suffering from depopulation (Molendijk 1992, Rybka 2015). This demographic pattern is also characteristic of the Kari'na Amerindians (Cariban), whose villages are interspersed with those of the Lokono. ${ }^{3}$ Both the Lokono and the Kari'na are commonly known in Suriname as benedenlandse Indianen (lit. 'down-country Indians') as opposed to the bovenlandse Indianen (lit. 'up-country Indians'), who live in the southern part of the country (see Carlin, this volume). The geographic proximity of the Lokono communities to non-Amerindian settlements, both historically and synchronically, has facilitated interaction between the Lokono and the newcomers to the Guianas. It is partly due to the intensity of such contact and the various socioeconomic pressures concomitant with it that the vitality of the Lokono language diminished drastically. In Suriname, the population of native speakers is shrinking, with the estimated number oscillating somewhere between one hundred and hundred fifty speakers today, a mere $5 \%$ of the ethnic Lokono population (Rybka 2015, 2016).

A great majority of the speakers are multilingual in Lokono, Surinamese Dutch, and the local lingua franca Sranantongo. Sranantongo is an English-based creole, the vocabulary of which shows also Dutch, Portuguese, and Kikongo influences. The moribund status of Lokono is evident from the fact that the speakers are on average above 50 . The younger generations have already shifted to Surinamese Dutch and Sranantongo, though there is a sizeable community of semi-speakers boasting various levels of passive and active knowledge of Lokono. Sranantongo and Surinamese Dutch have become the daily means of communication in the

3 The endonym Kari'na corresponds in the literature to the term Carib and Galibi with reference to the eastern dialects in French Guiana. For the contact situation of Kari'na in French Guiana, see Rose and Renault-Lescure (2008). 
villages in their respective domains. On the whole Surinamese Dutch is used in more formal contexts as a token of social distance and respect. Sranantongo, as a more intimate language, dominates less formal situations. Lokono in turn is hardly used today at all, at best between elderly spouses within their homes. The data presented here come from a corpus of narratives, recorded together with a number of fluent Lokono speakers in Suriname. The examples are presented in an orthography developed and adapted by the community (Rybka 2013). The standardization and popularization of the Lokono orthography are processes that are symptomatic of the revival of the interest in the Lokono culture within the community. The speakers themselves are aware of both language attrition and contact-induced language phenomena in Lokono. So much so, that they recognize the category of “deep” Lokono. "Deep” Lokono stands for half-forgotten vocabulary items and morphosyntactically more complicated expressions. It is opposed to the type of speech used by most speakers characterized by simplified grammar and lexical and structural borrowing. In all three nation states, the Lokono people are actively trying to document their language and engage in language revitalization projects (see Rybka 2015).

For the discussion of recent contact-induced language phenomena, the endangered status of the language raises an important question: what is a contact-related change and what is a symptom of language attrition? In light of the fact that Lokono is barely spoken today we can also ask what contact-induced language change is in a community in which any language phenomenon has little fertile ground to spread beyond the idiolects of the individual speakers? This problem applies particularly to the recent changes in the language, especially the structural influence of Sranantongo and Surinamese Dutch. In this chapter, I do not attempt to answer these questions. It is, however, important that the reader bears these points in mind when reading through the examples presented here, some of which at this stage may represent language changes characteristic of idiolects rather than the language as a whole.

\section{Lexical borrowing in a historical perspective}

Morphosyntactically, irrespective of the source language, borrowings are fully integrated into the Lokono grammar. Most lexical borrowings in Lokono also undergo a process of phonological adaptation. Typically, this involves imposing a syllable structure common among Arawakan languages - that is, $\left(C_{1}\right)\left(C_{2}\right) V\left(C_{3}\right)$, where $\mathrm{C}_{2}$ can only be a glide and $\mathrm{C}_{3}$ can be a glide or a nasal. Spanish arcabuz 'an obsolete matchlock firearm' became therefore arakabosa 'gun' and Dutch 
schaap and Sranantongo skapu 'sheep' were integrated into Lokono as shikâpo. The quality of the epenthetic vowel is often dictated by rules of vowel harmony. Moreover, as typical of many Arawakan languages, in Lokono there is no phonological distinction between the back vowels / $\mathrm{u} /$ and /o/ (Aikhenvald 1999, Patte 2002). Rather $[u]$ is the result of assimilation of $/ o /$ before $/ \mathrm{i} /$. In the communitybased orthography, all allophones of $/ \mathrm{o} /$ are written as $\langle 0\rangle$ (the grapheme $<\mathrm{u}\rangle$ stands for $/ \dot{i} /)$. The allophone $[u]$, found only before an [i], explains, for instance, why Spanish borrico 'donkey' is pronounced in Lokono with an [u]. However, some borrowings resist such phonological adaptation. The nouns bôtoli 'bottle' and kofi 'coffee', for instance, are pronounced with an [o] despite the following [i]. This reflects the fact that the languages from which these last two borrowings originate are in current use in the community, strengthening the original pronunciation. The older Spanish borrowings are not transparent anymore while those from creole languages and their lexifiers sometimes are and occasionally retain their original pronunciation.

The borrowed vocabulary can contain phonemes absent in Lokono, for instance, the velar voiced stop, which is rare in Arawakan languages, and the palatal fricative, which is unknown to Arawakan languages. These are often reanalyzed. The Spanish gallina 'chicken' became therefore karhina, with a voiceless velar stop and a retroflex $/ \mathfrak{r} /$. However, on other occasions, the borrowed material strengthens phonemic oppositions that are weak or absent in Lokono. The phoneme /p/, for instance, has today a vague status in Lokono, as it has hardly any minimal pairs with /b/ or /f/ (into which it developed). There are few native Lokono words that have a /p/, among them a number of fossilized place names, which shows that /p/ was indeed once a fully-fledged phoneme in Lokono. It is thus not surprising that foreign vocabulary with the phoneme /p/ is easily integrated into Lokono and represents today the majority of forms with a $/ \mathrm{p} /$.

\subsection{Amerindian interaction sphere}

The oldest layer of non-native words in Lokono comprises terms denoting culturally salient tools, plants, and animals, which the Lokono language shares with other genetically unrelated Amerindian languages of the region (e.g. Cariban, Waraoan) and even with languages no longer present on the linguistic map of the area (e.g. Tupian). Take as an example the word tokai 'oval house used as the medicine-man's outhouse', 'enclosure', 'closet', which is also found in Wapishana (Arawakan), Kari'na (Cariban), and is possibly cognate with the Tupi word tokaya 'a hiding place where one lies in wait when shooting game', 'a poultry-house' 
Tab. 1: Examples of nouns shared by the Amerindian languages of the Guianas.

\begin{tabular}{lll}
\hline Lokono & Other languages & Meaning \\
\hline maraka & maraka $(\mathrm{K}, \mathrm{T}, \mathrm{Pm}, \mathrm{Wp}, \mathrm{W}, \mathrm{Tu})$ & rattle \\
pamo & bamu $(\mathrm{W})$ & salt \\
samarhi & semari $(\mathrm{K})$, & cassava grater \\
& simari $(\mathrm{Wy}, \mathrm{T}, \mathrm{Pm}, \mathrm{Kp}, \mathrm{Ap}, \mathrm{M})$ & \\
manarhi & manare $(\mathrm{T}, \mathrm{Wy}, \mathrm{Ap})$ & cassava sieve \\
yowâna & iwana $(\mathrm{T}, \mathrm{Wy})$ & iguana \\
\hline
\end{tabular}

(de Goeje 1928b: 251). A similar example is the old-fashioned flute known to the Kari'na as kuwama, named after a thick type of bamboo out of which it is made. The bamboo is also known as kuwama to other Cariban groups such as the Trio, Kapon, and Pemon, but also to the Warao and the Lokono as kamwata. Another example is the noun karokori, which appears in Arawak, Wapishana, Trio, Kapon, Pemon, Apalai, and Wayana with the meaning 'gold', 'copper', or 'ornament'. The term was also recorded in the sixteenth century in the Calima region on the Pacific coast - a Colombian mining area, where an alloy of gold and copper used to be produced (Benjamin 1988). It is uncertain whether this root is related to kuri, a Quechua and Aymara word for gold, which would suggest an even further geographic spread of this vocabulary item. Tab. 1 lists more examples of the Amerindian shared lexicon (see also Renault-Lescure 2005, 2009 and Carlin, this volume). ${ }^{4}$

Such vocabulary reflects the existence of an Amerindian interaction sphere in the past, within which items and ideas were exchanged together with their labels, through trade, intermarriage, war, and other contact scenarios. The time depth of this layer remains uncertain but it may date back to pre-Columbian times. The degree of cultural convergence on the one hand, and cultural specialization on the other, within this Amerindian network can be gleamed from the literature (Roth 1915, 1924, 1929; de Goeje 1928a, 1930, 1942; Penard and Penard 1907-1908). It is, however, only recently that comprehensive studies of trade routes and commodities exchanged along them have appeared (Eriksen 2011; Bel 2015). A thorough analysis of the spread of the linguistic labels for such items, including their source languages and the intermediary languages that spread them further, is called for.

4 The abbreviations used in the chapter include: Lokono (L), Kari'na (K), Warao (W), Trio (T), Kapon (Kp), Pemon (Pm), Apalai (Ap), Wapishana (Wp), Macushi (M), Wayana (Wy), Tupi (Tu), Surinamese Dutch (D), Skepi Dutch Creole (Sk), Berbice Dutch Creole (Br), Sranantongo (Sr), Spanish (Sp), English (E), French (F). 


\subsection{The Spanish influence}

The lexical borrowings from Spanish - mostly nautical terms, terms related to colonization, and words for imported animals and tools - verbalize the Lokono experience of the first encounter with the Europeans and of the subsequent intensive trade with them. This period of contact started in 1510, when the Lokono began trading food with the Spanish on the barren pearl islands off the coast of today's Venezuela. The period ended roughly around the turn of the sixteenth century, when Antonio de Berrio attempted to colonize Trinidad, then inhabited by the Lokono as well, which led to an Amerindian opposition against the Spanish, and their subsequent alliances with the English and the Dutch (Boomert 1984; Benjamin 1988; Baarle 1995). Boomert (1984) describes three stages in the development of the communication between the Spanish and the Lokono: (1) the initial use of body language and gesture, (2) the subsequent employment of Lokono slaves as translators by the Spanish (ca. 1521), and (3) the period when Lokono let their sons grow up with the Spanish inhabitants of the island of Margarita, so that they could acquire Spanish (ca. 1550). Such changes in the communication patterns suggest that the Lokono quickly took the burden of communication upon themselves. This in turn speaks volumes for the importance of the Spanish trade to the Lokono community. The Lokono not only exchanged important goods with the colonial power but also traded them with other Amerindians further south who did not have direct access to the Spanish. The Spanish language continued to be influential on the Catalan Capuchins' missions on the Orinoco River from 1724 until 1817. Later the missions were destroyed in the independence turmoil and the Lokono, together with other Amerindians of the missions, moved to the basin of the Moruca River in the present-day Guyana. Historical sources explicitly mention Spanish as the language that was taught to the Amerindians by the Catalan Capuchins; no mention is made of the Catalan language (Benjamin 1991). Bearing in mind that the use of Catalan in Spain as a language of education was prohibited throughout the eighteenth century, there is no reason to believe that the Lokono were exposed to Catalan. Pierre (1988) provides more information on the complex history of the Spanish speaking Amerindians in the Moruca, who until today often bear Spanish sounding surnames.

Tab. 2 gives examples of borrowed terms for fauna (for more examples see Jubitana 1998; Penard and Penard 1927; Baarle 1995). The same borrowed Spanish vocabulary resurfaces in many languages of the Guianas, showing that the Amerindian languages shared the same lexical gaps and filled them in with Spanish loans (see Carlin, this volume). Considering the trading networks mentioned earlier and the geographic proximity of the Lokono to the colonizers, 
Tab. 2: Examples of Spanish loans denoting animals.

\begin{tabular}{llll}
\hline Lokono & Gloss & Spanish & Gloss \\
\hline karhina & chicken & gallina & chicken (female) \\
pêro & dog & perro & dog (male) \\
baka & cattle & vaca & cow (female) \\
kawayo & horse & caballo & horse (male) \\
\hline
\end{tabular}

Lokono certainly served as an intermediary language through which many of the Spanish loans entered other Amerindian languages.

Interestingly, the borrowing of animal terms involved a slight semantic shift in Lokono. In Spanish, the meanings of the four nouns given in Tab. 2 include biological gender of the animal. Such nouns are also often opposed to a lexeme denoting the other gender. In Lokono, simplex terms for animals do not encode gender. They are all grammatically feminine irrespective of the biological gender of the referent, which can only be specified by the addition of wadili 'male' or hiyaro 'female' to form a compound such as wadili pêro, lit. 'man dog'. The more general architecture of Lokono, in this case the gender system, has thus to a certain extent shaped the borrowing process, broadening the meaning of the original Spanish terms.

\subsection{The colonizers and the Creoles}

The influence of Dutch on Lokono starts at the beginning of the seventeenth century, with the foundation of the first colony on the Pomeroon River and later on the Berbice River. The English arrive in the middle of the seventeenth century and settle first on the Suriname River. In the beginning, the relations between the Lokono and the colonizers were mostly based on trade and providing various services (e.g. as guides). There were occasional alliances against the Spanish or the Kari'na but the slave trade greatly complicated the sociopolitical scene, leading to Amerindian uprisings and the final recognition of the "free Indians". Post-holders - intermediaries between the Amerindians and the colonizers - were appointed from the end of the seventeenth century and centered Amerindian communities around them. So did the Moravian missionaries between 1740 and 1808 in Berbice and Suriname, providing a more stable context for language contact.

Dutch- and to a lesser extent English-derived lexemes often found their way into the Lokono lexicon not directly, but through the medium of the Creole languages, of which they were the lexifiers. Dutch was the lexifier language of the mutually intelligible but now extinct Skepi Dutch Creole spoken on the Esse- 
quibo River and Berbice Dutch Creole spoken on the Berbice River. English is the lexifier of Sranantongo and the Guyanese Creole, today's lingua francas of Suriname and Guyana, respectively. The Lokono used Creole languages in contacts with the colonizers at least since the nineteenth century, though it is quite likely that the pattern has an even longer history. In the nineteenth century there were already Lokono communities who spoke Berbice Dutch Creole as their mother tongue (Robertson 1988). It is a fact too that Berbice Dutch Creole is heavily influenced by Lokono vocabulary (Kouwenberg 1994). The intensification of contacts between the Lokono and the non-Amerindian population from the beginning of the twentieth century, facilitated mainly by the Roman Catholic missionaries, gave momentum to the processes of shift toward Surinamese Dutch and Sranantongo and the concomitant increase in borrowings from these languages.

Baarle (1995) gives a list of loans from Surinamese Dutch and Sranantongo, most of which denote everyday items introduced by the colonizers, filling lexical gaps in the Lokono language. Apart from such borrowings there are also loans referring to new concepts. Unmentioned by previous studies is the fact that Surinamese Dutch numerals are quickly replacing the native numerical system, a consequence of the fact that learning to count comes early in the exclusively Dutch school curriculum and is a prerequisite to participation in cash economy. Another interesting example is the vocabulary for the days of the week, which had no native equivalents. Words such as Mandakha 'Monday' include the Lokono enclitic $=k h a$ which typically expresses temporal simultaneity of the predicate in a subordinate clause with that in the main clause. To the Lokono, Mandakha must have literally meant 'the time of manda', in keeping with other Lokono temporal expressions such as adalikha 'dry season', literally 'the time of adali 'sun'. Tab. 3 gives a few examples of borrowed terms for everyday tools and items.

As Baarle (1995) points out, the attribution of such loans to a particular Creole or one of the lexifier languages is often a matter of speculation and minute phonological detail. In most cases, it is probably better to think of the sources of these borrowings not in terms of 'either X or Y' but rather in terms of 'both X and Y'. It

Tab. 3: Sample of loans of from Creoles and their lexifiers based on Baarle (1995).

\begin{tabular}{lll}
\hline Lokono & Meaning & Possible sources \\
\hline bôtoli & bottle & $\begin{array}{l}\text { bottel (D), bodl (Sk), bodlo (Br), botella (Sp), bottle } \\
(\mathrm{E}), \text { bouteille (Fr) }\end{array}$ \\
lêpele & spoon & lepel (D), lepcl (Sk, Br) \\
sâka & bag & zak (D), sak (Sk), saka (Br), saca (Sp) \\
sêpo & soap & zeep (D), sepu (Sk), shepu (Br), sopo (Sr) \\
tafra & table & tafel (D), tafl (Sk), taflu (Br), tafra (Sr) \\
\hline
\end{tabular}


is a misconception to think in a diachronic perspective of Lokono as a language influenced by different languages in a simple chronological order. Rather the different communities spread across the Guianas came under the influence of different languages - be they Amerindian languages, Creoles, or their lexifiers - both simultaneously and consecutively, and in a fashion that often cannot be traced back. Some of these languages have vanished from the linguistic map of the area, while others are still part of it, strengthening borrowings that might have originally entered Lokono from a different source language.

\subsection{Contact-induced coinage}

The Lokono are not only passive receivers of foreign lexical material but also keen inventors of their own terms for non-native items. The most numerous group of such formations are terms coined with the instrument nominalizer - kwana. Take as an example the noun phrase faretho darhidakwana 'bus, taxi, car', meaning 'white man's instrument for moving quickly'. The phrase includes faretho 'white man' functioning as the possessor of a nominalization derived with the instrument nominalizer from the verb darhidin 'move quickly'. The instrument nominalizer was used productively in coining names for tools that have a clear function. Tab. 4 gives a few more examples (see also Penard and Penard 1927).

In the case of such complex phrases, linguistic changes can sometimes point to cultural changes. All instrument nominalizations are inalienably possessed: they require a possessor. With nominalizations denoting non-native tools, the possessor is by default faretho 'white man'. Nominalizations denoting native instruments are in turn possessed by person prefixes (or full nouns) indicating the true possessor. Returning to the nominalization of the verb darhidin 'move quickly' discussed above, wadarhidakwana, literally 'our tools for moving quickly' containing the first person plural prefix $w a-$, denotes dugout canoes.

Tab. 4: Examples of Lokono coinages with the instrument nominalizer.

\begin{tabular}{llll}
\hline Lokono & Native instrument & $\begin{array}{l}\text { Foreign } \\
\text { instrument }\end{array}$ & Root \\
\hline dukhukwana & pupil of an eye & mirror & dukhun 'see' \\
darhidakwana & dugout & car & darhidin 'move quickly' \\
balutukwana & traditional bench & chair & balutun 'sit down' \\
birakwana & toy & toy & biran 'play' \\
rhukukwana & $?$ & scissors & rhukun 'cut' \\
\hline
\end{tabular}


Until recently, the same nominalization could thus mean either 'car' or 'dugout', and the possessor was the de facto disambiguating device. Tab. 4 gives two more examples of such derivations with double interpretations. Today, the Lokono use cars, tools, and instruments originally associated with the colonizers. The noun faretho is therefore often replaced by the prefix indicating the true possessor of the vehicle, tool, or instrument, reflecting the changes in the life of the people that took place.

Such coining of new terms, though not a new phenomenon, has gained momentum recently, as part of the revival of interests in Amerindian heritage. Today, words that have been identified as borrowings by the speakers tend to be avoided and replaced with native terms. The noun pulata 'money' from plata (Sp) is now often replaced with khaborokhodo, meaning literally 'the thing in the hand'. Another example is kokoronoto 'coconut' from kronto, kokronto, krontonoto (Sr), which is replaced by kodibio matokonkoro, literally 'the one that the birds do not peck'. This revived interest in coining new terms and the rejection of older borrowings is particularly noticeable in the speech of the Lokono language activists. As such, it is a linguistic marker of the language revitalization movements in the community.

\subsection{Integration of Dutch and Sranantongo roots as verbs}

A phenomenon not discussed earlier in the literature on Lokono, most likely because of its recent nature, is the creation of hybrid verbs based on Surinamese Dutch and Sranantongo roots and Lokono morphology by the multilingual Lokono speakers. This phenomenon marks a new period in the history of the Lokono - the time of multilingualism in Sranantongo and Surinamese Dutch, which makes it possible for complex borrowing patterns to emerge. Tab. 5 lists such verbs attested in the corpus. The hybrid verbs are structurally complex forms, containing the verbalizer $-d V$ attached to a foreign root.

The hybrid verbs are active verbs - that is, verbs denoting an activity rather than a state - a class of verbs that combines with the person prefixes to express the subject. Semantically, the hybrid verbs do not form a coherent group. Some of them fill lexical gaps, for instance, lishidin 'read', doserdun 'bulldozer', reidwan 'drive', fabricierdun 'manufacture', and tiridin 'lead'. The closest Lokono equivalents of the verb bowdun 'build', for instance, are the semantically broader marhitin 'make' and semantically narrower shikwatwan 'build a house'. The verb bigindin 'begin' is an interesting case as the hybrid verb is an auxiliary verb and not a content verb. The Lokono lexical equivalent inatun to some speakers is still clearly related to ina 'base', from which it was derived with the 
Tab. 5: Hybrid verbs with Sranan and Dutch roots.

\begin{tabular}{llll}
\hline Lokono & Root & Gloss & Etymology \\
\hline tiridin & tiri (Sr) & lead, rule & sturen (D) \\
krindin & krin (Sr) & clean & clean (E) \\
laidin & lai (Sr) & fill, load & laden (D) \\
tandonon & tan (Sr) & stay, live & stay (E) \\
bigindin & bigin (Sr) & start, begin & begin (E), beginnen (D) \\
bowdun & bow (Sr) & build & bouwen (D) \\
lishidin & leisi (Sr) & read & lezen (D) \\
lolodon & lolo (Sr) & roll & roll (E) \\
fishidin & fisi (Sr) & fish & vis (D), fish (E) \\
doserdun & doser (Sr) & bulldozer & bulldozer (D,E) \\
bokodon & buku (Sr) & push & $?$ \\
reidwan & rei (Sr) & ride, drive & rijden (D), ride (E) \\
dankidin & danki (Sr) & thank & dank (D) \\
sekidin & seki (Sr) & cut with a saw & zaag (D) \\
menstruerdonon & menstrueren (D) & menstruate & menstrueren (D) \\
regedwan & regelen (D) & settle & regelen (D) \\
fabrisirdun & fabricieren (D) & manufacture & fabriceren (D) \\
\hline
\end{tabular}

verbalizer $-t V$. As such it, can only be used in the context of starting something from its ina 'base', for instance, in the context of making a basket.

In other contexts, a combination of specialized suffixes must be used to express the inceptive aspect. For other speakers, inatun is already an equivalent of the Sranan bigin, which in itself is a possible semantic extension of the meaning of the Lokono verb influenced by the contact languages. Other hybrid verbs such as lolodon 'roll', fishidin 'fish', or menstruerdonon 'menstruate' have Lokono equivalents that are in common use and well-known to the speakers. This suggests that the borrowing process is, at least partly, a rather spontaneous phenomenon. To the speakers, most of the hybrid verbs have a status of transparent ad-lib borrowings, often looked back upon with embarrassment. Importantly, these forms are fully incorporated into the morphosyntax of Lokono and take on the usual tense, aspect, and mood markers as in (1)..$^{5}$

(1) Mamenstruerdononthikwan, nei ôsama boma.

ma-menstruerdo-nõn-t $t i-k w \tilde{a}-\eta$

PRIV-menstruate-REFL.NMLZ-SBJ.REL:M-CONT-NMLZ

nei o:sa-ma b-oma

5 Glosses used are given in the list of abbreviations at the end of the chapter. 
3PL:H go-ABIL 2SG-COM

'But the ones who are kind of not menstruating anymore, they can go with you.'

The above example comes from a narrative about the rules that menstruating women have to obey in order not to anger the water spirit oriyo: they can only go into the creeks when they are not menstruating anymore. In (1), the hybrid verb menstrurdonon 'menstruate' appears in its reflexive nominalized form, prefixed with the privative $m a-$ and followed by a number of suffixes, including the relativizer $-t h i$, the continuative adverbializer $-k w a$, and the event nominalizer $-n$. The preposed complex nominalization is coreferential with the subject of the following clause.

The hybrid verbs are structurally complex forms, containing the verbalizer $-d V$ attached to the root, which integrates the verbs into the Lokono morphosyntax by providing them with an important root-final vowel, while leaving the roots intact. The root-final vowel of Lokono active verbs expresses a fourfold distinction that resurfaces in all forms of the verb. In theory, this means that each Lokono root can form up to four different active verbs illustrated in Tab. 6 .

Looking at the nominalized forms of the verbs, we can identify the first type as having a harmonized vowel. Such verbs are typical transitive verbs; they require a direct object, for instance, yalokhoton 'exchange something'. The second type ends in an $-a$ instead of the harmonized vowel. Such verbs are introversive; they foreground the activity as such and do not allow a direct object, for instance, yalokhotan 'change places'. The third type ends in $-o$ and includes reflexive verbs, for instance, yalokhotonon 'change a piece of garment'. This type is also characterized by a special form of the event nominalizer -non. Additionally some roots can form a fourth type in $-w a$, which is both introversive and reflexive at the same time, for instance, yalokhotwan 'dress up'. Within the paradigm of each of the four types, the vowel alternates to indicate the realis-irrealis distinction. Considering the crucial distinctions expressed by the root-final vowel of active verbs, the addition of the verbalizer $-d V$ to foreign roots can be seen as a practical

Tab. 6: Active verbs types (nominalized form).

\begin{tabular}{|c|c|c|}
\hline Type & Lokono native verb (nominalized) & Hybrid verbs (nominalized) \\
\hline 1 & yalokhot-o-n 'exchange something' & lolodon 'roll' \\
\hline 2 & yalokhot-a-n ‘change places’ & bukudan 'push' \\
\hline 3 & yalokhot-o-non 'change a piece of garment' & menstruerdonon 'menstruate' \\
\hline 4 & yalokhot-wa-n 'dress up’ & reidwan 'drive around' \\
\hline
\end{tabular}


device. The suffixation of $-d V$ leaves the foreign roots intact, while allowing to make the distinctions typical of the Lokono verb system.

The fact that we have not found a full set of four verbs illustrating each type for any of the hybrid verbs is a mere corpus gap. The hybrids do show the same set of distinctions as the native verbs, as shown in Tab. 6 above, which includes an example of a hybrid verb from each of the four types. Moreover, example (2) below exemplifies two hybrid verbs based on the same root, showing that such verbs can form the typical Lokono sets. In the example below, the morpheme $-d V$ is glossed as a combination of the verbalizer and the root-final vowel (v), which for reasons of clarity I do not gloss in other parts of the chapter.

(2) Yontho thobokodâka, tohobe to, bokodathe.

$\begin{array}{ll}y \tilde{o}-n-t^{h} O & t^{h} o-b o k o-d-a-k a \\ \text { LOC.ANPH-LOC-SBJ.REL:F } & 3 \mathrm{~F} . \mathrm{S}_{\mathrm{A}}-\mathrm{push}-\mathrm{VBZ}-\mathrm{V} 2-\mathrm{PFV} \\ \text { to-ho-be to } & b o k o-d-a=t^{h} e \\ \text { DEM:F-EMPH-COL DEM:F } & \text { push-VBZ-V1=VEN }\end{array}$

'Where they made a clearing (lit. pushed), these [trees], [they] cleared toward here.'

Example (2) comes from an elicitation session during which the speaker described pictures of landscape; in this case a picture of a road. The foreign root boko appears here twice: first in combination with the verbalizer and the vowel typical of introversive verbs that do not allow a direct object (type 2), and second with the vowel typical of the paradigm of transitive verbs (type 1).

Sranantongo roots are as a rule ambiguous between a verbal and non-verbal word class status. Hence, krin can either mean the verb 'clean' or the adjective 'clean', and lai can have both a verbal reading 'load' but also a nominal interpretation 'cargo', depending on the syntactic context in which it is placed. This ambiguity is one of the defining features of the Sranantongo lexicon and grammar. Dutch verbs allow such ambiguity only in their infinitival form. In Lokono, the distinction between nouns and verbs is also vague. The tense, aspect, and mood suffixes and enclitics can be attached to any part of speech, as in (3), in which the abilitative marker appears on a noun.

(3) Ayomuntho orhorhokoma kiba no.

$\begin{array}{lll}\text { ayomĩn- } t^{h} o & \text { ororo-koma } & k i b a=n o \\ \text { high-SBJ.REL:F } & \text { landform-ABIL } & \text { also }=3 \mathrm{~F} . \mathrm{s}_{\mathrm{O}}\end{array}$

'It can be a mountain too (lit. 'landform that is high').'

Importantly, the hybrid verbs cannot be thought of as nouns that were borrowed and then verbalized, as none of the Sranantongo or Dutch roots appears in the corpus as a noun. I assume therefore that in this case it is the need to provide the 
Tab. 7: Verbs derived with the verbalizer $-d V$.

\begin{tabular}{lllll}
\hline POS & Root & Gloss & Derived form & Gloss \\
\hline noun & khoi & spittle & khoidin & spit \\
stative verb & tata & strong & tatadun & strengthen \\
reduplicated & dia & talk & diadiadun & converse \\
ideophone & dudu & belch & dududududakwan & make the sound of belching smoke \\
\hline
\end{tabular}

roots with the defining features of active verbs - the root-final vowel - that motivates the process. Active verbs are the only part of speech characterized by the presence of the root-final vowel and its alternations. The addition of the verbalizer $-d V$ serves the purpose of providing the foreign roots with the formal exponent crucial to the proper functioning within the Lokono grammar. It is worth noting that the suffix $-d V$ can be attached to almost any part of speech in Lokono in order to derive an active verb. Tab. 7 shows how it combines with a noun, a stative verb, a reduplicated stem, and an ideophonic stem.

Below I give one more example of the use of $-d V$ to form a verb. Here a reduplicated verbal root is combined with two exclamations, and the whole complex is followed by the verbalizer $-d V$ forming a particularly complex predicate.

(4) Beroberoakhaseidâkwa latha li konokokoya.

$$
\begin{array}{ll}
\text { bero bero- } a k^{h} a-s e i-d a:-k w a & l-a=t^{h} a \\
\text { ITR groan-EXCL-EXCL-VBZ-CONT } & 3 \mathrm{M} . \mathrm{S}_{\mathrm{A}}-\mathrm{E} . \mathrm{V}=\mathrm{RPRT} \\
l i \quad \text { konoko-koya } & \\
\text { DEM:M forest-spirit } &
\end{array}
$$

'The forest spirit kept groaning with pain, they say.'

(Baarle et al. 1989: 16)

Interestingly, in Baure (Arawakan), the suffix - $\check{c}$, serving a similar function of deriving transitive verbs from intransitive verbs, but also verbalizing nouns and adjectives, occurs also as an "obligatory final part of the base" in all Spanish loan verbs (Danielsen 2007: 243). A similar phenomenon is also noted for Kari'na (see Rose and Renault-Lescure 2008; Alby and Renault-Lescure 2012). Such mechanisms appear to be at work in a number of Amerindian languages in contact, most likely helping integrate the foreign language material into the highly synthetic grammar of the target languages. 


\section{Structural borrowing}

Structural borrowing requires a prolonged contact situation, in which the borrowing party is for the most part familiar with the source language (Thomason and Kaufman 1988; Matras and Sakel 2007). Though creole languages have been used by the Lokono in contacts with the colonizers at least from the beginning of the nineteenth century, they did not have a strong structural influence on Lokono language itself until quite recently. Bilingualism in Surinamese Dutch and Lokono is an even more recent phenomenon. However, the complex borrowing patterns in the verbal domain described above suggest that at present the degree of multilingualism should favor structural borrowing. In the following two subsections, I demonstrate that this is indeed the case. Lokono bears marks of the structural influence of Sranantongo and Dutch, which also do not remain unaffected by Lokono. Below I look first look at the traces of the Lokono influence on Dutch and subsequently at the impact of Dutch and Sranantongo on the grammar of Lokono.

\subsection{The influence of Lokono on the local variety of Surinamese Dutch}

The case of transferring Lokono structures into the contact languages, Surinamese Dutch and Sranantongo, has been less documented than the influence in the opposite direction. Lexical borrowing from Lokono and Kari'na into Creole languages did, however, take place, and sometimes on a noticeable scale, as was the case with Berbice Dutch Creole (Kouwenberg 1994). Cases of structural influence, however, have not been reported. The influence of Lokono on local Surinamese Dutch appears even more limited. Dutch became a language used on a daily basis in the communities only recently and its domains of use are limited to formal contexts. There are no studies that focus on the way Surinamese Dutch is spoken by the Lokono or any other Amerindians of Suriname. Under certain conditions, however, lexical and structural transfers from Lokono into Surinamese Dutch are possible and should be studied more systematically. Greetings that a stranger often hears in a Lokono village, of the type given in (5), are one example of such a transfer.

(5) Ben je aan het wandelen?

ben je aan het wandel-en

COP.2SG 2SG on DEF wander-INF

'Are you wandering about?' 
This somewhat odd-sounding greeting is in fact a loan translation of the typical Lokono greeting formula - a rhetorical question about what the addressee is doing. Such questions are pragmatically inappropriate as a greeting in standard Surinamese Dutch. Yet they are perfectly acceptable and relatively common in the multilingual environment of the Lokono communities. In Lokono, the exact form of such a greeting depends on what the addressee is actually engaged in. In principle, there are an infinite number of greetings, but a few most common activities, especially sitting and walking, are typically referred to. The pragmatic function of such questions is close to that of: How do you do? When meeting someone who is walking through the village, the right greeting is therefore one of the following:

(6) a. Buyâdwabo?

bu-ya:dwa-bo

2SG.S ${ }_{\mathrm{A}}$-wander-PRG

'Are you wandering about?'

b. Yâdwâko babo?

ya:dwa:-ko $\quad b-a-b o$
wander-CONT $\quad 2$ sG.s ${ }_{\mathrm{A}}-\mathrm{E.V}-\mathrm{PRG}$
'Are you wandering about?'

The greetings are formed around the verb yâdwan 'wander', which functions either as a predicate on its own as in (6a) or, when adverbialized with the help of the continuative suffix, forms part of a complex predicate with the semantically empty verb $o / a$, as in (6b). The correct answers to such a greeting is confirmatory echo expressions, given in (7). Failure to echo the question has connotations such as irritation, arrogance, or even flirting, depending on the context and tone. Interestingly, the affirmative particle $\mathrm{uhm}$ in (7) is also non-native. The Lokono equivalent is a stressed ehei or unstressed ehe.

(7) a. Uhm, dayâdwabo.

$$
\begin{aligned}
& \text { ihm da-ya:dwa-bo } \\
& \text { yes } 1 \text { SG.S }_{\mathrm{A}} \text {-wander-PRG } \\
& \text { 'Yes, I am wandering.' }
\end{aligned}
$$

b. Uhm, yâdwâko dabo.
ihm ya:dwa:-ko
$d-a-b o$
yes wander-CONT 1SG.S ${ }_{\mathrm{A}}-$ E.V-PRG
'Are you wandering about?'

Formally, the Lokono and the Surinamese Dutch greetings could be hardly any more different from one another. What we witness here is therefore not a straightforward copying of the Lokono structure but an attempt at recreating 
the semantics and pragmatics of the original with the building blocks of a completely different system. The differences are many. In Lokono questions are not marked by inversion, a characteristic of the Surinamese Dutch system, but by sentence intonation. Surinamese Dutch lacks morphological marking of the progressive aspect, which it expresses by a periphrastic construction with the verb zijn 'be' and the prepositional phrase headed by aan 'on', the complement of which is a infinitival from of the content verb. The Surinamese Dutch greeting rebuilds the Lokono structure from scratch using the means available in the language.

Similar loan translations of greetings in Sranantongo have not been attested, though one hears more Sranantongo in the villages than Surinamese Dutch. The rules of social conduct are the main reason for this absence. What dominates the choice between Surinamese Dutch and Sranantongo is politeness. It is impolite to start a conversation with a stranger in Sranantongo. It is the usual routine to begin in Surinamese Dutch and slowly gravitate toward a more intimate language - that is, Sranantongo - while the connection between the speech participants grows stronger and their linguistic repertoires become evident by occasional switches. Due to these pragmatic considerations, Surinamese Dutch is therefore the default target language in the case of borrowing of greeting patterns.

It should be noted that this type of borrowing lingers somewhere between a structural and a lexical borrowing. It recreates a whole grammatical structure, but it has little influence on the grammar of the language besides this particular salutatory context. Such greetings could be treated as lexicalized phrases, which would relegate the described phenomenon to the domain of lexical borrowing. In any case, the example serves to show that under certain circumstances the borrowing process can take place from Lokono into Surinamese Dutch, necessitating that this type of phenomena be studied more carefully.

\subsection{The influence of Sranantongo and Surinamese Dutch on local Lokono}

Though the collected data focus on native speakers' use of Lokono, there are numerous traces of structural influence of Sranantongo and Surinamese Dutch in the corpus. In the remainder of this chapter, I present the case of the Sranantongo grammatical element taki and functionally related forms, showing that the structural borrowings rely heavily on the structures available in both the source and the target language, and result in the introduction of new categories into Lokono. 


\subsubsection{Sranantongo 'taki' and its functions}

In Sranantongo the grammatical element taki introduces direct speech - that is, it functions as a quotative (de Kleine 2002: 228). It is also identical to the verb taki meaning 'say, speak', form which the quotative derives. The diffusion of the quotative taki further induced the grammaticalization of the Surinamese Dutch verb $z e g$ 'say' into a quotative as well. Apart from its use as a quotative, taki functions also as a complementizer "joining that which is said, perceived, or known to the main clause" (Nickel and Wilner 1987: 30). As a complementizer, the use of taki is restricted to complements expressing a fact and a potential (e.g. with the verb howpu 'hope'), but not an activity (see Dixon 2006 for the typology of complements). The form taki is therefore not only a quotative but also a complementizer of verbs or speech, perception, and cognition with certain types of complements (facts and potentials). In both its functions, taki precedes the elements it introduces, the quote or the complement, respectively. Since the form taki has influenced the grammaticalization of the verb zeg 'say' in Surinamese Dutch, the official language and the language of prestige, it can be expected that it also had impact on Lokono.

\subsubsection{Impact on Lokono direct speech}

In Lokono, most recounted speech acts are rendered in a direct fashion, indirect speech having a limited use. A direct speech utterance consists of the quote itself and an accompanying speech-act tag - a phrase stating who said it and to whom. In such tags, the speaker is encoded by a person prefix attached to an empty verb. The addressee is invariably marked by the dative mun. The empty verb has the form of a single vowel: either [o] or [a] depending on the tense, aspect, and mood suffix that is attached to it. The empty verb plays the role of a verbum dicendi in the speech-act tag. It can take on the typical verbal markers but its precise translation as 'said', 'asked', or even 'thought' is inferred from the context. Such a tag normally follows the quote, though in exceptional situations it can precede it. Both positions are illustrated in the dialogue between the blind man and Jesus given in (8) and (9), taken from a biblical narrative.

(8) Adayali mikodara, "Boborata de," la lumun.

$\begin{array}{lllll}\text { adayali } & \text { mikodara } & \text { bo-borata=de } & 1-\mathrm{a} & \text { li-mĩn } \\ \text { God } & \text { sender } & \text { 2SG.A-help=1SG.0 } & \text { 3M.s } \text { A }_{\text {-E.V }} & \text { 3M-DAT }\end{array}$

'God's missionary, "Help me," [the blind man] said to [Jesus].' 
(9) Ken lidinama li Jezus. La namun: "Hishikathe dâmuni."

\begin{tabular}{|c|c|c|c|}
\hline kẽ & li-dinama & Jezus & \\
\hline and & 3M.s $\mathrm{A}_{\mathrm{A}}-$ stand.up & DEM:M Jesus & \\
\hline$l-a$ & $n a-m \tilde{t} \eta$ & $h i-\int i k a=t^{h} e$ & $d-\operatorname{a:min}=i$ \\
\hline & 3PL:H-DAT & 2PL.A-give=VEN & $1 \mathrm{sG}-\mathrm{by}=3 \mathrm{M} . \mathrm{O}$ \\
\hline
\end{tabular}

In examples (8) and (9), which come from a Bible translation workshop, we see the speech-act tag first following and then preceding the quotes. The latter order can be explained in this case by an attempt at the rendition of the biblical style. Coincidentally, we witness here therefore another layer of borrowing - that of discourse practices. Coming back to the question of a possible borrowing of a quotative, the main purpose of which is to mark a quote, it is clear that such an acquisition would be functionally redundant in Lokono. In Lokono the vast majority of reported utterances are quotes. Moreover, function words tend to be borrowed with the rules for their linear ordering (Moravcsik 1978). Structurally taki is incompatible with the typical example of a Lokono direct speech. The quotative taki is pre-clausal in Sranantongo and requires the quote to follow it and the verbum dicendi to precede it. The Lokono speech-act tag containing the equivalent of a verbum dicendi typically follows the quote. Transplanting taki into Lokono as a quotative would therefore leave it stranded at the end or the beginning of a clause. At best, taki can cater only for a handful of discourse-marked quotes that follow the speech-act tag. In the corpus of narratives, I found in fact one such example, given in (10).

(10) Wa namun taki: "Wandakiatheda".

\begin{tabular}{|c|c|c|c|}
\hline$w-a$ & $n a-m \tilde{t} \eta$ & taki & $w-\tilde{a} n d a-k i-(h) a=t^{h} e=d a$ \\
\hline 1PL.S ${ }_{A}-\mathrm{E} . \mathrm{V}$ & 3PL-DAT & QUOT & 1PL. $\mathrm{S}_{\mathrm{A}}-$ arrive $-\mathrm{ADD}-\mathrm{FUT}=\mathrm{VEN}=\mathrm{DIRECT}$ \\
\hline
\end{tabular}

Example (10) comes from a narrative explaining why the villages are depopulated. In (10) the speech-act tag comes first followed by the quotative, as would be the case in Sranantongo. Structurally strenuous and functionally redundant, the process of borrowing taki as a quotative is nevertheless limited to such rare examples.

\subsubsection{Impact on complementation strategies}

Complementation strategies used with verbs of speech, perception, and cognition are in turn a target for the structural influence of taki, the complementizer. Indirect speech in Lokono is in general restricted to utterances introduced by questions words. 
The verb dian 'talk' can only combine with nouns denoting languages and clauses introduced by question words. A few verbs such as âdakoton 'ask' and khoyabun 'beg' can introduce indirect speech by employing a nominalization strategy. However, in Sranantongo taki does not combine with the equivalents of these complement-taking predicates - that is, begi 'beg' and aksi 'ask'. The complementizer taki does not have therefore any influence Lokono clauses with the verbs of speech.

The situation is different with verbs of cognition and perception. In Lokono, these can employ either of the two complementation strategies: (1) using a nominalization or (2) using a paratactic construction. The first strategy is exemplified in (11), which comes from a traditional story about an old woman who wants to marry her daughter to the right candidate.

(11) Liki deitha dukhunima dasa khona.

$\begin{array}{lll}l i-k i & d-e i t^{h} a & d \dot{i} k^{h} \dot{i}-n-i-m a \\ \text { 3M-SPEC } & \text { 1sG.A-know } & \text { look-NMLZ-EPEN-ABIL } \\ d a-s a & k^{h} \text { ona } & \\ \text { 1SG-child } & \text { after } & \end{array}$

'He, whom I just described, I know he can take care of my child.'

In (11), the complement-taking predicate is the verb eithin 'know'. The complement has a form of a complex event nominalization. The event nominalizations are formed by the addition of the event nominalizer $-n$, which in (11) is also followed by the abilitative suffix. Importantly, the nominalizer is not a complementizer disguised in the form of an affix, as it covers all sorts of dependent clauses, not only complement clauses.

A paratactic construction, in which no nominalization is present, is shown in (12). In this case, the third person feminine enclitic is used to establish the relation between the two clauses.

(12) Meithin

$m-e i t \tilde{\imath}-\eta$

PRIV-know-NMLZ

$k a-d^{i} i b e y o-k a=t^{h} e$

ATR-belly-PFV=VEN

'They did not know it for sure; she became pregnant.'

(Patte 2003: 404) nada no, kadibeyokathe namunda no.

$$
n-a=d a=n o
$$

3PL:H.A-E.V $=$ DIRECT $=3 \mathrm{~F} . \mathrm{O}$

$n a-m \tilde{t} n=d a=n o$

3PL: $\mathrm{H}-\mathrm{DAT}=\mathrm{DIRECT}=3 \mathrm{~F} . \mathrm{S}_{\mathrm{O}}$ 
uninhibited. The positional obstacle observed with the empty verb is absent; the complement-taking predicate is followed by the complement, which matches the linear order of clauses in Sranantongo. Functionally, the introduction of a complementizer renders the relation between the complement-taking predicate and the complement clearer through overt marking that is more explicit than the event nominalizer. This is particularly important in light of the fact that the nominalizer can be omitted and parataxis can be used instead, in which case the relation between the two clauses is not marked in any way. Structurally unobstructed and functionally motivated, the borrowing of taki as a complementizer of verbs of perception and cognition, did indeed take place. In examples (13) and (14) the use of taki together with the verb of auditory perception is shown.

(13) Wakanabâka taki thudarhidikwana lokwâya lutikida.

wa-kanaba:-ka taki $t^{h} \dot{\boldsymbol{i}}$-daridi-kwana
1PL.A-hear-PFV COMP $3 \mathrm{~F}-$-run-INSTR.NMLZ
lok-wa:ya li-tjikida
inside-SRC $\quad 3 \mathrm{M} . \mathrm{S}_{\mathrm{A}}$-fall
'We heard that he fell out of a car.'

In (13) the nominalizer is absent and taki is the only marker showing the relation between the clauses in such a construction. In (14) the phonetically reduced variant of taki appears; this time together with the complement in the form of an event nominalization.

(14) Wakanaba tak wabarhosen Kasuporhinkili shokothokho nukamo

shikin wamun.

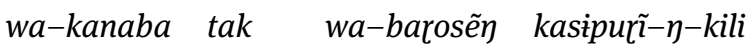

1PL.A-hear COMP 1PL-captain Cassipora-LOC-SPEC:M

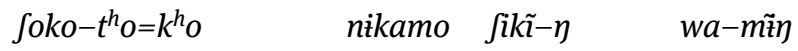

little-SBJ.REL:F=NEG grief give-NMLZ 1PL-DAT

'We heard that our captain, the one who was in Cassipora then, gave us a lot of grief.'

The process of borrowing taki as a complementizer is not unrestricted. Although the verb of cognition eithin 'know' normally takes a fact complement, verbs of perception can often take both a fact and an activity complement. This is also the case in Lokono. As was mentioned earlier, taki introduces in Sranantongo only fact complements with verbs of perception, not activity complements. This restriction is maintained in Lokono. All instances of the use of taki with verbs of perception in the corpus represent fact complements. This distinction between fact and activity complements was unknown to Lokono before. Both fact and activity complements 
are normally expressed by the nominalization strategy or the paratactic strategy in Lokono. The introduction of taki resulted therefore in the creation of a new grammatical opposition: that between fact and activity complements.

\subsubsection{Clausal relations and factuality}

The use of taki as a complementizer of verbs of cognition and perception has been observed in the speech of only those Lokono who are fluent in Sranantongo and Surinamese Dutch. These speakers are relatively young, which suggests that the structural interference is a recent development. These phenomena are features of the idiolects of particular speakers rather than a widespread pattern in the language. It might be argued therefore that it is too early to call them borrowings. Keeping in mind the moribund status of the language and its restricted domains of use, it seems unlikely that such interference will have time to spread. Yet, though not particularly common among the speakers, the borrowing of taki is not a stand-alone process but part of a larger trend to mark the relations between clauses in a more overt way, which results in the introduction of other linkers. Sranantongo has indeed yet another complementizer, namely dati/dat, interchangeable with taki/tak, derived from the Surinamese Dutch complementizer dat. Examples with this complementizer are also found in the Lokono corpus.

(15) Want ama weithin akharoho dat madukhun tha wabithiro.

$\begin{array}{lccc}\text { want ama } & w \text {-eit } \tilde{\imath}-\eta & a k^{h} \text { aroho } & \text { dat } \\ \text { for what } & \text { 1PL.A-know-NMLZ now } & \text { COMP } \\ \text { ma-ditk } k^{2}-n & t^{h}-a & w a-b i t f i-r o & \\ \text { PRIV-look-NMLZ } & 3 \mathrm{~F} . \mathrm{S}_{\mathrm{A}}-\mathrm{E} . \mathrm{V} & \text { 1PL-LOC-ATL } & \end{array}$

'Because what we know now is that they do not look at us.'

Such examples are also limited to fact complements of verbs of perception and cognition. The conjunction want 'because' in (15) is also a borrowing from Surinamese Dutch (see also Sranan wanti 'because'). Beyond factual complements of verbs of perception and cognition, there are other linkers being borrowed. Non-factual complements of predicates of cognition are sometimes introduced in the speech of the same group of speakers by the Surinamese Dutch complementizer of 'if', similar in function to Sranantongo efu, which is cognate with the English if.

(16) Want meithin weikhan khidwaniabo of thandamathe thurubutamathe yâya we.

$\begin{array}{lllll}\text { want } & m-e i t \tilde{\imath}-\eta & \text { wei=k } k^{h} \tilde{a} \eta & k^{h} i d w a n i a b o & \text { of } \\ \text { because } & \text { PRIV-know-NMLZ } & \text { 1PL=DIM } & \text { really } & \text { COMP }\end{array}$




$$
\begin{aligned}
& t^{h}-\tilde{a} n d a-m a=t^{h} e \quad t^{h} \dot{i}-r i b i t a-m a=t^{h} e \quad y \hat{a} y a=w e
\end{aligned}
$$

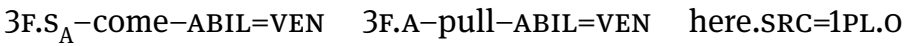

$$
\begin{aligned}
& \text { 'Since we don't really know whether they can come here and they can pull }
\end{aligned}
$$

In example (16), the complementizer of is used with an otherwise unmarked complement clause - that is, there is no nominalizer. Such complementizers further complicate the opposition between fact and activity complements by introducing a third category, namely complements that express a potential and are introduced by of. In the light of this, the introduction of taki is not a standalone process. On the contrary, it is part of a process of making the form and the contents of complement clauses more explicit by delimiting their beginning and signaling their factuality status. This phenomenon is part of an even larger picture. Lokono does not have a class of what could be referred to as sentence connectors. Instead, such functions are normally expressed by morphological markers such as the event nominalizer $-n$, the simultaneity enclitic $=k h a$, or postpositions such doma 'because' and bena 'after'. All of these appear after the verb in the subordinate clause in Lokono. The foreign sentence connectors that were borrowed - the already discussed complementizers taki, dat, of but also ma 'but', te 'until', and want 'because' - are unbound and appear preclausaly. Apparently they present a tempting option for the speakers of Lokono. The reasons for these borrowing processes are not fully understood yet but the borrowing of "utterance modifiers", as Matras (1998) calls them, is a widespread feature of contact. Matras (1998) argues that these grammatical elements are in fact most vulnerable to contact-induced changes. It should be pointed out that similar phenomena appear in other Amerindian languages in contact, such as Baure, an Arawakan language of Bolivia (Danielsen, p.c.), Kari'na (Rose and Renault-Lescure 2008) and others (Stolz 2001).

\section{Conclusions}

The history of contact between Lokono and other languages has left its imprint on the lexicon and grammar of the language, which is summed up in Tab. 8.

Lexical borrowing in the form of nouns forms the oldest layers of non-native vocabulary, whether of Amerindian, European, or Creole origin. Complex cases of lexical borrowing necessitating morphological operations in order to integrate the foreign material into the system of Lokono appeared quite recently in the verbal domain. These borrowings are often spontaneous and ephemeral but they also require a better command of the source language than the nominal borrowings 
Tab. 8: Lokono contact situations in a chronological perspective.

\begin{tabular}{|c|c|c|c|}
\hline Timeline & Contact languages & Setting & Linguistic result \\
\hline Pre-conquest & $\begin{array}{l}\text { Arawakan } \\
\text { Cariban } \\
\text { Tupian } \\
\text { Waraoan }\end{array}$ & $\begin{array}{l}\text { direct and indirect } \\
\text { contact through } \\
\text { constant barter of } \\
\text { commodities, ethnic } \\
\text { alliances, and exogamy }\end{array}$ & $\begin{array}{l}\text { borrowing of nouns for } \\
\text { culturally salient items }\end{array}$ \\
\hline Early colonial & $\begin{array}{l}\text { Spanish (and } \\
\text { Amerindian languages } \\
\text { as intermediaries) }\end{array}$ & $\begin{array}{l}\text { intensive trade and } \\
\text { the establishment of } \\
\text { missions }\end{array}$ & $\begin{array}{l}\text { borrowing of nouns for } \\
\text { foreign items (nautical } \\
\text { terms, weapons, clothes, } \\
\text { animals) }\end{array}$ \\
\hline $\begin{array}{l}\text { Establishment } \\
\text { of Creoles }\end{array}$ & $\begin{array}{l}\text { Creole languages and } \\
\text { Surinamese Dutch (and } \\
\text { Amerindian languages } \\
\text { as intermediaries) }\end{array}$ & $\begin{array}{l}\text { trade, alliances, } \\
\text { slavery, establishment } \\
\text { of missions and } \\
\text { post-holders }\end{array}$ & $\begin{array}{l}\text { borrowing of nouns for } \\
\text { items related to peaceful } \\
\text { occupation }\end{array}$ \\
\hline Present & $\begin{array}{l}\text { Sranan } \\
\text { Surinamese Dutch }\end{array}$ & $\begin{array}{l}\text { intermarriage, trade, } \\
\text { cash economy, } \\
\text { education, } \\
\text { multilingualism }\end{array}$ & $\begin{array}{l}\text { hybrid verbs and the } \\
\text { borrowing of } \\
\text { grammatical elements } \\
\text { and categories }\end{array}$ \\
\hline
\end{tabular}

did. Their appearance is most likely connected to the increase in multilingualism in Sranantongo, Surinamese Dutch, and Lokono. It is precisely this change in the linguistic repertoire of the speakers that made it possible for structural borrowing to take place. The examples presented here focus on the strategies for expressing relations between clauses. The data show a shift from post-modifying and often morphologically bound exponents to pre-modifying and free particles. The examples demonstrate also that such interference does not happen randomly but that it is driven by the resources available in both the source and the target language, and can result in the introduction of new categories into the language (e.g. factuality).

\section{Abbreviations}

A

ABIL

ADD

ATL

COL

$\mathrm{COM}$ agent (subject transitive verb)

abilitative

additive

atelic

collective

comitative 


\begin{tabular}{|c|c|}
\hline COMP & complementizer \\
\hline CONT & continuative \\
\hline $\mathrm{COP}$ & copula \\
\hline DAT & dative \\
\hline DEF & definite \\
\hline DEM & demonstrative \\
\hline DIM & diminutive \\
\hline DIRECT & direct knowledge evidential \\
\hline E.V & empty verb \\
\hline ЕMPH & emphatic \\
\hline EPEN & epenthetic \\
\hline EXCL & exclamation \\
\hline F & feminine \\
\hline FUT & future \\
\hline $\mathrm{H}$ & human \\
\hline INF & infinitive \\
\hline INSTR.NMLZ & instrument nominalization \\
\hline ITR & iterative \\
\hline LOC & location \\
\hline LOC.ANPH & locative anaphoric pronoun \\
\hline M & masculine \\
\hline NEG & negation \\
\hline NMLZ & (event) nominalizer \\
\hline $\mathrm{O}$ & object of a transitive verb \\
\hline PFV & perfective \\
\hline PL & plural \\
\hline PRIV & privative \\
\hline PRG & progressive \\
\hline QUOT & quotative \\
\hline REFL.NMLZ & reflexive (event) nominalization \\
\hline RPRT & reportative \\
\hline $\mathrm{S}_{\mathrm{A}}$ & subject intransitive active verb \\
\hline SBJ.REL & subject relativizer \\
\hline SG & singular \\
\hline $\mathrm{s}_{\mathrm{O}}$ & subject intransitive stative verb \\
\hline SPEC & specificity \\
\hline SRC & source \\
\hline vBZ & verbalizer \\
\hline VEN & venitive \\
\hline
\end{tabular}


Brought to you by | Universiteit Leiden / LUMC 